\title{
DEPOIMENTOS DE ENFERMEIRAS HOSPITALARES DA DÉCADA DE 60: SUBSÍDIOS PARA A COMPREENSÃO DA ENFERMAGEM ATUAL
}

Edna Paciência Vietta e col *

VIETTA, E.P. et al. Depoimentos de enfermeiras hospitalares da década de 60: subsídios para a compreensão da enfermagem atual. Rev.Latino-am. enfermagem, Ribeirão Preto, v. 4, n.2, p. 23-39, julho 1996

Este estudo é parte de um projeto mais amplo que visa resgatar aspectos significativos relacionados à evolução da assistência de enfermagem nas décadas de 500 90. Este resgate é feito através da técnica de depoimentos orais de enfermeiros em exercício e aposentados, no contexto de um Hospital Escola do interior Paulista. O presente estudo particulariza os resultados obtidas, referentes à década de 60. Como resultado evidencia-se o esforço empreendido pelos enfermeiros na luta pelo reconhecimento e prestígio da profissão, as transformações intensa e profundas aos novos papéis da enfermeira enquanto líder da equipe e membro da equipe médica.

UNITERMOS: enfermagem, evolução da assistência de enfermagem, hospital-escola

\section{INTRODUÇÃO}

No intuito de buscar compreender as transformações ocorridas na assistência de Enfermagem no Brasil, no período de 1950 a 1990, um grupo de pesquisadoras empenhou-se em tal tarefa de investigação, procedendo o resgate de depoimentos pessoais (através da obtenção de memórias vivas) de enfermeiros. Dada a amplitude

* Bolsistas do PROJETO INTEGRADO CNPq. Processo Ref. 502500/91-3: Luciana Villela Bueno; Marilene da Fonseca Magalhães; Anália Ribeiro Heck e Marlene Uchara 
de abrangência e perspectivas envolvidas por tal região de inquérito o grupo optou por delimitá-la, numa primeira instância, ao Universo de um hospital escola.

Tal escolha justifica-se pelo fato de ser, sobretudo neste contexto, que as inovações tiveram ao longo destas décadas o ambiente propício para suas implantações, devido a sua vinculação às Escolas de Enfermagem estaduais e atuação efetiva, direta e indireta, das lideranças intelectuais da profissão.

Em trabalho retrospectivo realizado, pelo referido grupo relativo à década de 50 apreendeu-se que esta foi uma década marcada por intensas e profundas transformações da sociedade como conseqüência da Revolução Industrial do século XVIII. Estas mudanças atingiram também a Enfermagem já sobejamente carregada das marcas e influências da década antecedente. A profissão de Enfermagem absorveu 0 pensamento funcionalista, adotando uma tendência administrativa, voltada para a divisão de trabalho com diferenciação de elementos que distinguia o profissional enfermeiro propriamente dito, daqueles encarregados pela execução de simples tarefas rotineiras, de aprendizagem mais ou menos rápida e que não exigiam muitos conhecimentos. A nova cadeia de comando colocou o enfermeiro graduado (da década de 50) numa posição de responsabilidade pela 1 supervisão das ações dos outros elementos do serviço.

Não obstante, o método funcionalista foi pouco a pouco contestado sendo desencorajado enquanto modelo de atuação. Foi identificado como inapropriado, por traduzir-se em fragmentação de cuidado a ser oferecido ao paciente. Acrescia-se a isto, o fato de a enfermeira tomar-se cada vez mais distante do paciente (MENDES et ai., 1984).

Outra influência significativa na evolução da assistência de Enfermagem na década de 50 foi o da Teoria das Relações Humanas favorecendo a implantação do modelo de equipe. Esta teoria foi uma reação à Escola Clássica de Administração tendo como precursores Elton Mayo \& Kurt Lewin apud ETZIONI (1967).

O trabalho de equipe foi definido na década de 50 como Método de Trabalho, visando a um objetivo comum, permitindo seus integrantes fazerem o melhor uso de suas qualidades pela combinação de suas habilidades e experiências (LAMBERTSEN, 1953).

No final dos anos 50 e início dos anos 60, com o impacto dos reflexos da segunda grande guerra, houve intensificação das pesquisas sobre comportamento individual e em grupo, sobre as diferenças e necessidades individuais, motivações e lideranças. Esta influência mudou o foco da Enfermagem fazendo com que a assistência antes centrada na tarefa se deslocasse na assistência centrada em necessidades humanas básicas, tendo como referencial a Teoria de MASLOW, 1954.

Por considerar-se o trabalho da Enfermagem na década de 50, um trabalho de equipe, deu-se grande importância à capacidade de estabelecer relações humanas considerada susceptível de desenvolvimento, através do estudo das Ciências Sociais, principalmente, a Psicologia e a Sociologia. 
Neste modelo, a Enfermagem como líder da equipe assumiu a administração da assistência delegando, contudo, certas responsabilidades do cuidado direto a membros da equipe, tomando só para si a responsabilidade pelo planejamento, coordenação e a supervisão da assistência.

Pela análise dos depoimentos emitidos por enfermeiros da década de 50 concluiu-se que embora sem preparo adequado, a enfermeira dessa época assumia atividades administrativas, confirmando seu papel de liderança da equipe de Enfermagem e membro da equipe de saúde. No esforço em conciliar suas varias atribuições, a enfermeira realmente delegava algumas de suas funções, procurando não se afastar do cuidado direto ao paciente. Embora sem muita autonomia e pouca autoridade, lutava para manter seu espaço conquistando respeito e reconhecimento por sua competência e facilidade em adaptar-se às transformações tecnológicas - Destacase a importância dos valores éticos e morais da profissão sob a influência da adoção do Código de Ética do Conselho Internacional de Enfermeiros, adotado no Brasil na década de 50 (VIETTA et al., 1992).

Em continuidade ao trabalho de pesquisa sobre a década de 50 , já referenciado passou-se a investigar a evolução da assistência na década de 60 , utilizando-se dos mesmos procedimentos e técnicas do depoimento pessoal. Procurando acompanhar os mesmos passos levantaram-se, inicialmente, dados sobre os acontecimentos significativos da década de 60 , revisando a literatura especializada, sobretudo, as revistas de Enfermagem (REBEn de 1960 a 1970 e Anais de eventos científicos de Enfermagem ocorridos no referido período).

Apreendendo os aspectos de destaque, encontrar-se a preocupação em focalizar a Ética salientando o estabelecimento e a divulgação dos três princípios considerados fundamentais para a postura ética da profissão: respeito à natureza humana; relação do homem para como seu semelhante; direção vertical do homem a Deus (TURKIEWICZ, 1965): Esta referência mostra o reflexo do impacto da adoção do Código de Ética do Conselho Internacional de Enfermeiros 1953, e da preocupação que adentrou a década de 60 .

A partir de 1960, com a realização do XIII Congresso Brasileiro de Enfermagem realizado em Belo Horizonte, a atenção central dirigiu-se ao programa de ética a ser ministrado nas Escolas de Enfermagem.

Muito importante também foi o trabalho de investigação promovido pelas Comissões de Ética e de Educação, levado a efeito por Glete de Alcântara e Marina de V. Forjaz, sobre "Ensino de Ética nas Escolas de Enfermagem" publicado por ocasião do XIII Congresso em julho de 1960 (ALVIM, 1965).

Na década de 60, pela primeira vez é estabelecido um currículo mínimo para o ensino universitário no Brasil, incluindo-se o de Enfermagem (SILVA et al., 1979).

Segundo ALCÂNTARA (1964), com o enquadramento das Escolas de Enfermagem ao nível de ensino superior, o Conselho Federal de Educação (CFE), em 1962 fixou em três anos o Currículo Mínimo do Curso de Graduação em Enfermagem. Este currículo negligenciou a recomendação vigente de Recursos e Necessidades de Enfermagem sobre a importância da inclusão de disciplinas de 
Cultura Geral, ou estudo de humanidades. Na oportunidade a autora, lamenta que o CFE tenha fixado o curso em três anos no momento em que o elevava à nível universitário.

Com o parecer do Conselho Federal de Educação 271/62, percebe-se uma mudança considerável no currículo de Enfermagem com enfoque sobre as clínicas especializadas de caráter curativo.

Evidencia-se um ensino voltado para a área hospitalar, quando, segundo SILVA et ai. (1979), o parecer 271/62, negando as raízes históricas da Enfermagem, no Brasil, exclui o ensino de Enfermagem de Saúde Pública e das Ciências Básicas do curso de graduação. O currículo preconizava o ensino das ciência físicas e biológicas, levando a visão do homem, como ser biológico. Contrariava, portanto, todas as considerações apregoadas no documento da OPS/OMS o "GUIA PARA ESCUELAS DE ENFERMERIA EN LA AMERICA LATINA" (1961), não obstante o esforço empreendido por lideranças da Enfermagem brasileira no sentido de melhorar o ensino e a prática profissional. Neste intuito foram realizados inúmeros seminários dos quais resultaram anti-projetos curriculares (SILVA et al., 1979).

Em 1962, com a portaria número 94162 de 27/03/62, do Ministro de Estado dos Negócios do Trabalho e Previdência Social o enfermeiro conquista a posição de autonomia profissional, criando o grupo de enfermeiros como profissão liberal. Até então, os enfermeiros eram mantidos numa situação irregular, situados na categoria de "enfermeiros e empregados de hospitais e casas de saúde, inclusive duchistas e massagistas" (SILVA et al., 1979).

A análise da situação da enfermeira existente na América Latina sugeria às Escolas a revisão de seus currículos, recomendando o abandono de métodos de ensino tradicionais em busca de novos rumos para a educação das enfermeiras.

Quanto aos objetivos de um serviço de Enfermagem, o guia estabelecia que se a escola tivesse como preocupação o preparo da enfermeira, os serviços deveriam se preocupar em primeiro lugar com o bom atendimento dos pacientes. Na realidade admitia a existência de uma estreita inter-relação, pois não poderia haver bom atendimento de pacientes, senão houvesse formação de bons profissionais, e não poderia haver bom preparo de enfermeiros sem um bom campo de aprendizado. Sendo assim um serviço de Enfermagem deveria colaborar na formação destes profissionais (CHJARELLO, 1963).

Na década de 60, destaca-se a Lei Orgânica da Previdência Social, primeiro passo para a unificação previdenciária que se verificou em 1966. Sua rede de hospitais e ambulatórios era insuficiente para atender à demanda, passando então o Instituto Nacional de Previdência Social (INPS) a ser o grande "comprador" de serviço do setor privado (OLIVEIRA, 1979; ALMEIDA et al., 1981).

Neste período a situação econômica do País sofre grave crise, surgindo a preocupação pela racionalidade dos gastos com a saúde. Persiste a hegemonia da assistência curativa sobre a prática preventiva.

Surge um movimento de crítica orientada para a conscientização da necessidade de integração de aspectos curativos e preventivos até então oferecidos 
pelas instituições de saúde. Passa a considerar hospital moderno a instituição de conotação dinâmica, não limitada apenas em receber doentes, mas assisti-los de forma mais ampla ou seja não apenas ao nível curativo mas preventivo e educativo estendendo este atendimento à família e à comunidade assim a instituição passa a realizar não só as tarefas básicas de curar mas, também a de reabilitar, prevenir, educar, pesquisar e ensinar (ALMEIDA, 1957).

A Enfermagem passa a ser conceituada como um processo interpessoal que considera o indivíduo em sua totalidade como membro de uma família e de uma comunidade com atividades dirigidas a promoção, proteção e recuperação da saúde (PEPLAU, 1952).

NOGUEIRA (1965, p. 372), afirmava: "hoje nossa Enfermagem não se restringe à assistência curativa, mas atua na profilaxia das doenças, visando à consideração dos fatores sociais e econômicos, senão como determinantes, pelo menos como componentes das condições de doença".

O desenvolvimento da ciência ou mesmo da arte da Enfermagem se faz imprescindível para o desenvolvimento da profissão. Somente com o uso da metodologia científica é que ela poderia equacionar com mais objetividade as áreas de dificuldades (OLIVEIRA, 1963).

As enfermeiras da década de 60 compreenderam que a prática de seu exercício só alcançaria a fase de maturidade com o desenvolvimento da pesquisa em Enfermagem.

Com base no exposto e entendendo que: 1 - o sentido que atribuímos as coisas de hoje, está estritamente ligado ao entendimento que temos do passado; 2 - a maneira como desempenhamos nosso papel na sociedade depende do ponto em que nos encontramos neste percurso e no diálogo que traçamos entre o passado e o presente; 3- a memória faz recuperar os acontecimentos da história, permitindo-nos a inserção na totalidade desta realidade de modo a podermos agir sobre esta, é que nos propomos a pesquisar a década em questão, estabelecendo os seguintes OBJETIVOS:

a) resgatar alguns aspectos da assistência de enfermagem hospitalar na década de 60 ,

b) identificar aspectos da enfermagem atual referidos pelos enfermeiros da década de 60.

\section{METODOLOGIA}

Embora haja especificidades em termos de vivências em nível regional e tipo de hospital (particular, estatal e de ensino) onde essas vivências ocorreram, optou-se no presente estudo pela investigação em um hospital 
escola do interior paulista, limitando a amostra aos 8 (oito) enfermeiros formados na década de 60 , em exercício neste hospital, presentes no período estipulado para a coleta de dados e que aceitaram participar do estudo.

Para tanto, foi utilizada da técnica da história oral, cujo termo amplo recobre uma quantidade de relatos a respeito de fatos não registrados por outro tipo de documentação, ou cuja documentação se queira complementar (SIMSONS, 1988).

Coletadas por meios de entrevistas, esta técnica registra a experiência de um indivíduo (enquanto representante de uma coletividade) ou de vários indivíduos de uma mesma coletividade.

A técnica utilizada envolve a modalidade de depoimentos pessoais, exigindo formas específicas de desempenho do pesquisador. Da vida do informante só interessam os acontecimentos que se inserem diretamente no contexto do trabalho. Conhecendo o problema ou a temática a ser focalizada, busca-se obter do narrador o essencial, dispensando o que é supérfluo e desnecessário para a análise dos dados. O pesquisador tem sob seu controle o enfoque do depoimento através de estratégias empregadas durante as entrevistas e direciona o depoimento para aspectos relevantes para a compreensão da temática a ser focalizada. No caso da presente investigação, a estratégia utilizada foi um roteiro previamente elaborado, avaliado por 3 pesquisadores (em termos de clareza, objetividade e adequação) em plano piloto.

Mesmo que o pesquisador venha registrar um número reduzido de depoimentos, seu objetivo é captar a idéia do grupo, a sociedade de que ele é parte. Busca, portanto, captar a coletividade a partir dos indivíduos. Não se trata de considerálos isoladamente, nem de compreendê-los em sua individualidade o contrário, o que se pretende é captar através de seus depoimentos o que se passa no interior da coletividade da qual participam ou são membros integrantes. Os sujeitos não são individualizados, eles agora são pessoas representativas, não sendo nem mesmo necessário nominá-los. Todavia, no anonimato, esses indivíduos contém num microcosmo as configurações que sua coletividade abarca, ao ordenar umas em relações às outras unidades, de que se compõem o grupo.

Corroborando as idéias de que a quantidade não significa necessariamente qualidade, temos o pensamento de DURKHEIM (1963, p. 86), para o qual ... não é a quantidade de fatos registrados que conduz a conhecimentos novos e sim, a análise cuidadosa de fatos decisivos e cruciais.

A coleta de dados inicialmente foi dada aos sujeitos à liberdade de expor sua experiência, através de relato, partindo de duas questões norteadoras: "Como era a assistência de Enfermagem na década de 60?": "Como é ou está a Enfermagem hoje?". Após o relato foi oferecido ao enfermeiro um roteiro a ser consultado para complementação de seu depoimento, cujo objetivo foi tentar a abrangência da temática e homogeneização do conteúdo dos oito depoimentos.

Segundo a preferência dos sujeitos, o relato oral foi obtido através da 
utilização da técnica do gravador em local e tempo pré-determinados. Após as entrevistas o material foi imediatamente transcrito e posteriormente categorizado segundo o Modelo de GIORGI, adaptado por VIETTA et al. (1992) para o presente estudo.

Este procedimento propiciou uma retomada do conteúdo dos depoimentos, favorecendo o procedimento de análise em profundidade.

Para tal seguiram-se os seguintes passos:

- leitura cuidadosa do conteúdo total dos depoimentos com vistas a apreensão do seu significado na estrutura global;

- releitura de cada depoimento e procedimento de cortes nos relatos, tendo por base, em primeiro lugar, temas mais amplos e em seguida temas específicos, relevantes para a compreensão e análise da temática em questão;

- agrupamento destes recortes em categorias visando à identificação de pontos comuns nos oito depoimentos, na ordem dos questionamentos de inquietação;

- e finalmente, análise da temática destes agrupamentos tendo em vista o objetivo maior: resgate da evolução da Enfermagem e a atuação na década de 60 .

\section{ANÁLISE DOS DEPOIMENTOS}

Os sujeitos falam em choque das gerações para expressarem sua indignação no confronto das décadas de $60 \mathrm{com}$ a década atual, mostrando de certa forma que a Enfermagem de hoje pouco tem haver com a Enfermagem de seu tempo.

“... o choque das gerações também atingiu a Enfermagem. E difícil acreditar que a de hoje é neta da de ontem e que pertencem a mesma arvore genealógica..."

Os sujeitos expressaram em seus relatos que na década de 60 , houve uma ampliação do campo da atividade do enfermeiro, havendo necessidade de adaptação a uma nova realidade.

“... o campo para a enfermeira era vasto, muito havia de ser feito...”

“... a atuação de enfermagem foi ampliada abrangendo além das tarefas básicas outras mais complexas a ela delegadas..."

Percebe-se um empenho da enfermeira da década de 60 em assumir este espaço. Uma certa satisfação em conseguir corresponder a este apelo ou necessidade. 
Esta conquista é carregada por um senso de responsabilidade acrítico, porquanto, embasado em atitudes de submissão às normas, rotinas e cumprimento de ordens. No entanto, esta submissão parece dotada de aspectos pessoais relevantes e persistentes ao longo da história da Enfermagem.

“... a Enfermagem dos anos 60 era mais submissa às normas e rotinas..."

“... sempre houve uma certa submissão da Enfermagem em relação aos médicos e acho que isso não mudou muito, embora em algumas áreas, pela atuação de algumas enfermeiras o trabalho chegasse a ser feito numa relação de cooperação e respeito num mesmo nível..."

Esta relação de subordinação era também uma característica das lideranças entre enfermeiros e subordinados chefes e subalternos, divisão de Enfermagem e chefias.

Como à enfermeira faltava preparo administrativo suficiente para o exercício da função de liderança. Ao se ver pressionada a assumir a chefia, tinha como único recurso o poder de autoridade que lhe era conferido na função determinada.

“... a direção da Divisão de Enfermagem ditava normas geralmente rígidas sem permitir discussão, aqueles que se atreviam a discutir ou discordar eram de certa maneira marginalizados..."

“... as chefes de enfermagem utilizavam-se do poder de autoridade e eram extremamente exigentes em termos de disciplina e obediência..."

Apreende-se também que a década de 60 foi pautada por um clima de transição havendo situações de superação de barreiras e de dificuldades.

“... bons tempos aqueles em que no plantão noturno, por falta de médicos residentes, a enfermeira assumia responsabilidades profissionais que a elevavam na equipe de saúde. Por outro lado para não trazer desconforto ao paciente o médico executava certas técnicas de Enfermagem como $o$ cateterismo vesical em homens. Nesta harmonia do trabalho o beneficiado era o paciente..."

“... a enfermeira era a líder da equipe na sua unidade de trabalho, participava das visitas médicas, relatava as condições dos doentes, as ocorrências nos plantões, e sua opinião era considerada..."

"... a hierarquia era muito respeitada e todos se tratavam por "senhor" e "senhora", mesmo os alunos..." 
As enfermeiras da década de 60 entendiam que este respeito era parte do compromisso ético e da postura profissional preconizava pelos princípios da moral profissional.

“... o profissional era orientado a respeitar os princípios éticos e morais e se considerava que a postura, a atitude profissional e o respeito à hierarquia eram importantíssimos para a manutenção desses valores..."

“... a Enfermagem era respeitada dentro da equipe de saúde pela dedicação e empenho no trabalho..."

“... apesar da postura médica de "todo poderoso" a enfermeira sempre gozava de bastante respeito por parte deles, porém, cumpria ordens, raramente discutia..."

“... a moral e a ética eram cumpridas rigorosamente..."

Segundo esses relatos, a postura da enfermeira atual mudou em dois aspectos: no da submissão considerada positiva e no do compromisso com a profissão considerada por eles como negativo.

“... hoje percebemos que a equipe de Enfermagem já está menos submissa, discute quando não concorda, tem mais facilidade também em se colocar frente a equipe médica..."

“... mas, percebemos que existe menos compromisso com o trabalho e desempenho... a grande maioria trabalha objetivando o salário mensal..."

A enfermeira da década de 60 se refere ao relacionamento enfermeiro paciente como uma preocupação de sua década e crítica a atuação da enfermeira atual neste aspecto considerando como fator negativo para a questão da valorização e reconhecimento profissional.

“... o doente era conhecido e só se referia a ele pelo nome, a enfermeira sabia de todos os seus pacientes, inclusive sua situação familiar..."

“... hoje vemos que a enfermeira deixou de ser a líder de fato dentro da equipe de Enfermagem, ela já não é, de maneira geral, tão respeitada, não sabe mais de todos os seus pacientes, parece meio perdida, na burocracia..."

Os relatos confirmam que as enfermeiras da década de 60 exerciam suas 
atividades prestando cuidados integrados, curativos e reabilitadores focalizando 0 paciente como membro de uma família e integrante da sociedade.

“... a enfermagem prestava cuidados integrais ao paciente e familiares estando atento as suas relações sociais..."

Quanto aos sentimentos em relação às mudanças e transformações mencionadas, os sujeitos manifestaram certas perdas.

“... a enfermeira prestava cuidados de fisioterapia, assistência social e atendimento emocional. Com o tempo foi cedendo a essas atribuições e pouco ou nada fez para colocar outras coisas no lugar".

“... a enfermeira ao acompanhar o desenvolvimento tecnológico, aprendeu a trabalhar com muitos aparelhos e muitas técnicas antes essencialmente manuais passaram a ser feitas pelos aparelhos..."

Suas críticas atingem mais profundamente as enfermeiras atuais ao referirem $p$ como improcedentes as justificativas geralmente apresentadas.

“... as desculpas não procedem... são os baixos salários, a incompreensão da equipe, a má formação que recebeu na escola, o desrespeito da equipe de saúde..."

Em suas opiniões existem outros fatores interferindo neste comportamento, alguns internos à profissão, outros às instituições e outros ainda, de caráter pessoal.

“... a Enfermagem tem tudo para ser uma grande profissão, pois há espaço e mercado de trabalho para todos os níveis, no entanto, a falta de união e organização da classe, põe tudo a perder..."

“... hoje com o aparecimento dos cargos hierárquicos a luta para galgar os degraus da escalada tornou-se selvagem..."

“... o que mudou é que antigamente havia mais amizade, um ajudava mais o outro..."

Os sujeitos mencionam a corrupção para descrever os mecanismos de entraves para o desenvolvimento da profissão.

“... há, vamos assim dizer... a corrupção: há tráfico de influências, clientelismo, parentesco e outras afinidades mais ..." 
Fica claro que a enfermeira da década de 60 sentia prazer no trabalho que executava, orgulho em ser enfermeira e o era por ideal.

“... quando iniciei meu trabalho, percebi que a enfermeira era um profissional muito valorizado, do qual se esperava o domínio do saber, principalmente na administração de toda sua área de atuação. Era o elemento coordenador, também era acima de tudo um idealista..."

“... considero a Enfermagem não apenas uma profissão, mas algo mais, uma vocação ..."

“... o trabalho era feito com muito humanismo sentia-se muito prazer em ser responsável pela saúde ou recuperação da saúde de um ser humano e a enfermeira costumava, quase que regra geral levar isso muito a sério ..."

O enfermeiro da década de 60 , fala com muito orgulho de sua satisfação pelo trabalho. Fala também de seu compromisso e engajamento na profissão.

“... trabalhava-se o maior número de horas por dia e não sentíamos tanta preocupação com o horário de ir embora. Parece-me que as enfermeiras eram mais felizes..."

“... percebemos hoje, com raras exceções que o profissional enfermeiro, chega mais inseguro, não, demonstrando satisfação nem o ideal que se espera, nem sempre se torna enfermeiro por opção e escolha..."

Detectam-se nos relatos, importantes críticas dos enfermeiros da década de 60 às situações de crise experienciadas pela profissão na atualidade, manifestadas por apreensões de conotação geral e específica. Críticas estas, ora dirigidas ao sistema de ensino do país, ora às escolas de Enfermagem e outras vezes à profissão como um todo.

“... na conjuntura social atual, dizemos que todo ensino está falido, do básico ao universitário, que o serviço público está inoperante e emperrado e a enfermagem não poderia estar diferente..."

Há de forma velada, uma certa insatisfação, das enfermeiras em relação à participação dos docentes das escolas de Enfermagem presentes nos campos de estágios do hospital.

“... as docentes tinham presença marcante no hospital e o relacionamento entre nós era muito bom..." 
“... antes as docentes da escola de enfermagem participavam ativamente do trabalho de campo..."

As representantes da década de 60, informaram que nesse período, a enfermagem progrediu muito em seu status e a escola deu muito de si ao hospital. Houve evolução, porém esta foi sentida de forma unilateral.

“... a partir daí a enfermeira evoluiu dentro da escola, como docente; o conhecimento científico começou a abrir novos horizontes, mas essa evolução foi unilateral e a escola aos poucos foi perdendo seu espaço dentro do hospital..."

As enfermeiras entrevistadas acreditam que o enfraquecimento do vínculo escola-hospital aconteceu gradativamente nas décadas posteriores, prejudicando e interferindo no processo de integração entre a teoria e a prática. Segundo os depoimentos, o aluno perdeu em termos de carga horária e de qualidade dos estágios, com desvalorização do desenvolvimento da habilidade técnica.

“... a escola de Enfermagem estava representada no hospital (referindo-se a década de 60) e a maioria de seus docentes trabalhava no mesmo, responsabilizando-se pelo atendimento ao paciente e orientação dos alunos..."

“... acreditamos que ao longo do tempo a escola de Enfermagem perdeu certo espaço dentro do hospital, os docentes passaram a se dedicar mais às pesquisas..."

Percebe-se certo ressentimento das enfermeiras de campo em relação aos docentes, por sentirem distanciamento entre si. As enfermeiras entendem esta mudança como deliberada e conseqüente a diferenças de graus de conhecimentos.

“... as docentes passaram a se considerarem melhores ou superiores às enfermeiras do hospital porque agora eram "doutoras"..."

Fica claro a necessidade do docente buscar integração ensino e pesquisa; maior integração e intercâmbios com as enfermeiras de campo. Maior integração entre a escola e o hospital, oferecimento de condições para ingresso dos enfermeiros de campo em programas de pós-graduação.

“... hoje sentimos uma certa distância e até barreira para o nosso crescimento..."

“... as docentes têm a teoria... mas nós temos a prática...”

Rev. Latino Am. Enf. - Ribeirão Preto - v. 4 - n. 2 - p. 23-39 - julho 1996 
“... hoje a Enfermagem modernizada, científica, não consegue aplicar os altos conhecimentos recebidos na Universidade..."

Essa deficiência é vista pelos sujeitos como conseqüência da formação acadêmica atual desvinculada da prática e maior importância dada ao saber do que ao fazer.

“... no entanto com o fazer a enfermeira supera o saber, é só estudar um pouco enquanto que o saber sem a prática nada significa".

“... as docentes devem entender que as enfermeiras têm muito a Ihes oferecer..."

“... a Escola de Enfermagem terá de voltar a ser um templo onde as pregações deverão ser cientificas sim, mas além de tudo, deverão ser humanizadas e a serviço do ser humano..."

Quanto ao currículo atual das escolas há também sérias críticas por parte dos enfermeiros da década de 60.

“... acreditamos que no currículo das escolas deve haver maior período de estágios, incluindo cuidados diretos com valorização de técnicas, pois a maioria dos enfermeiros atuais tem muitas dificuldades..."

“... a bagagem teórica é muito boa e precisa haver o equilíbrio com a prática..."

Segundo os relatos, a escola era bastante exigente em termos do ensino e aprendizagem. Dos alunos eram exigidos, sobretudo, disciplina, obediência e comportamento exemplar.

“... o ensino era muito rigoroso e levado a sério... a disciplina era como numa escola militar e em relação à obediência às normas ao comportamento e vestuário..."

As enfermeiras informam que ainda na década de 60 e até parte da década precedente, a escola em questão, manteve este perfil, sobretudo enquanto durou o regime de internato das alunas. Nesta década algumas alunas moravam em regime de internato na própria escola.

“... com o passar do tempo fui percebendo que o rigor de exigências foi diminuindo e a enfermagem não conseguiu achar um meio termo e a postura profissional principalmente sofreu grande deteriorização..." 
“... nos últimos tempos o nível do aluno caiu muito...”

Por outro lado as entrevistadas manifestam também uma certa preocupação em relação à evolução do nível da postura ética do enfermeiro ao longo do tempo.

“... a ética foi sendo deixada de lado e profissionalmente, perdemos muito. Saímos de um rigor absoluto para a permissividade... e fora do hospital público a situação é ainda pior..."

“... os valores morais e éticos eram levados muito a sério pelos enfermeiros... hoje deixa muito a desejar..."

No entanto, observa-se otimismo e esperança por parte das entrevistadas, quanto às perspectivas da enfermagem enquanto profissão. Mencionam que se há dificuldades, há também disposição e empenho em melhorar e sugerem algumas soluções. Entre ela a de que:

“... a escola deve manter uma maior aproximação com o hospital..."

“... há necessidade de reaver o vínculo entre docentes e enfermeiros de campo..."

“... a escola deve oferecer mais oportunidades às enfermeiras de campo nos cursos de pós-graduação..."

“... acho que a formação do enfermeiro é responsabilidade da escola. $A$ enfermeira tem que ter virtudes inerentes ao seu desempenho, competência, que vem do conhecimento, responsabilidade, sensibilidade, boa vontade, postura e discrição..."

“... a única alternativa para nos reerguermos nesta profissão é voltarmos às origens e trabalharmos ao lado do doente, de onde nunca devíamos ter saído..."

“... é necessário que o enfermeiro saiba que só é possível chefiar, coordenar um serviço de bom nível quando souber cuidar do doente integralmente..."

“... que a qualquer momento o enfermeiro possa provar que é capaz de ministrar esse cuidado melhor do que o atendente e $o$ auxiliar.

“... que o enfermeiro precisa "se fazer indispensável"..."

Rev. Latino Am. Enf. - Ribeirão Preto - v. 4 - n. 2 - p. 23-39 - julho 1996 


\section{CONSIDERAÇÕES FINAIS}

Segundo os relatos das enfermeiras da década de 60 houve mudanças relevantes na evolução da Enfermagem nas últimas quatro décadas. Entre essas mudanças destacam-se: a ampliação do campo de ação da enfermeira, o qual foi conquistado a partir da apropriação gradativa e acrítica de responsabilidades, porquanto embasado em atitudes de submissão às normas, rotinas e cumprimento de ordens. A década de 60 caracterizou-se por um clima de transição havendo situações de superação de barreiras e de dificuldades. A hierarquia era respeitada com rigor. $O$ profissional era orientado a respeitar os princípios éticos e morais e considerava que a postura, profissional e o respeito à hierarquia eram importantíssimos para a manutenção desses valores. Segundo os sujeitos as enfermeiras de hoje são menos submissas, discutem quando não concordam e têm mais facilidade em se colocar frente à equipe médica. Há muita competição entre os profissionais e uma luta para galgar postos. A enfermeira da década de 60 sentia satisfação no seu trabalho, orgulhava-se de ser enfermeira e escolhia a profissão por ideal. Segundo os sujeitos pesquisados o enfermeiro de hoje é mais inseguro, não demonstra satisfação e nem sempre opta pela Enfermagem por vocação ou ideal. As enfermeiras em seus relatos manifestaram críticas quanto ao sistema de ensino básico, às Escolas de Enfermagem, ao currículo de enfermagem, aos profissionais, à falta de integração entre docentes e enfermeiras de campo. Os sujeitos afirmam que os enfermeiros da era moderna, científica, não conseguem aplicar o conhecimento adquirido na Universidade. Sugerem que as escolas privilegiem mais a prática ampliando o período de estágios considerando a necessidade de maior equilíbrio entre teoria e prática. Os relatos confirmam que os cuidados de Enfermagem prestados na década de 60 eram voltados para o enfoque integrado com ações curativas, preventivas e reabilitadoras, abrangendo o paciente, a família e a comunidade. Sugerem como alternativa para reerguimento da profissão, a volta às origens e o reassumir do cuidado integral e diferenciado do paciente, tornandose imprescindível no contexto da assistência à saúde.

\section{DECLARATIONS OF REGISTERED NURSES FROM THE 1960s: ELEMENTS TO COMPREHEND NURSING TODAY}

This study is part of a more extensive project that proposes to recover significant aspects related to the evolution of nursing care from 1950s to 1990s. This report is made through the technique of oral declaration by active and retired registered nurses, in the context of an University-hospital from the interior of São Paulo State. The present study 
emphasizes the outcomes related 1960s. The results show the effort undertaken by nurses in the struggle for profession's recognition and prestige; intense and deep changes related to nurse's new roles as leaders of the nursing staff and members of the medical team.

\title{
DECLARACIONES DE ENFERMERAS HOSPITALARIAS DE LA DÉCADA DEL SESENTA: AYUDA PARA LA COMPRENSIÓN DE LA ENFERMARÍA ACTUAL
}

\begin{abstract}
Este estudio es parte de un proyecto más ámplio que apunta rescatar aspestos significadtivos relacionados a la evolución de la asistencia de enfermería en las décadas del 50 al 90. Este rescate es hecho a través de la técnica de declaraciones de enfermeros en ejercicio y pensionados, en el contexto de un Hospital Escuela del interior Paulista. El presente estudio particulariza los resultados obtenidos, referentes a la década del 60. Como resultado se evidencia el esfuerzo empreendido por los enfermeros en la lucha por elreconocimiento y prestigio de la prefesión, las transformaciones intensas y profundas a los nuevos papeles de enfermería, como líder del grupo de enfermería y miembro del equipo médico.
\end{abstract}

TÉRMINOS CLAVES: enfermería, evolución de la asistencia de enfermería, hospitalescuela

\section{REFERÊNCIAS BIBLIOGRÁFICAS}

01. ALCÂNTARA, G. Formação e aperfeiçoamento da Enfermagem em face das exigências modernas. Rev. Bras. Enfermagem, v. 17, n. 6, p. 408-419, dez. 1964.

02. ALMEIDA, A. S. A integração do hospital as saúde na saúde pública. Rev. Sev. Esp. Saúde Pública, v. 2, n. 9 dez. 1957.

03. ALMEIDA; M. C. P., SILVA, G. B.; RUFFINO, M. C.; GOMES, D. L. S.; ROCHA, S. Y. Contribuição ao estudo da prática de enfermagem - Brasil. Ribeirão Preto: Escola de Enfermagem de Ribeirão Preto - USP, 1981. 58 p. (mimeo).

04. ALVIN, E. de F. Levantamento de recursos e necessidades de enfermagem. Rev.

Bras. Enfermagem, v. 18, n. 4 p. 301-310, out. 1965. 
05. CHIARELlO, A. Relações ensino-serviço de enfermagem. Rev. Bras. Enfermagem, v. 16, n. 6, p. 261-266, dez. 1963.

06. DURKEIM, E. As regras do método sociológico. 2. Ed. São Paulo: Edição Nacional, 1963. p. 74-75.

07. ETZIONI, A. Organizações modernas. Trad. Mirim L. Moreira Leite, São Paulo: Pioneira, 1967.

08. GUIA PARA ESCUELAS DE ENFERMERÍA EN LA AMERICA LATINO. OPAS/OMS. Seminário de Diretoras de Escuelas de Enfermería. Paracas: Perú, set. 1961. 78 p. (Publicaciones Científicas, n. 55).

09. LAMBERTSEN, E. C. Equipe de enfermagem: organização e funcionamento. Trad. ABEn. Rio de Janeiro: SESPIABEn, 1953. p. 103.

10. MASLOW, A. H. Motivation and personality. New York: Harper and Brother, 1954.

11. MENDES, I. C. M.; TREVISAN, M. A.; MORIYA, T. M.; PACIÊNCIA, E.; WRIGAT, M. G. M.; RUFFINO, M. C. Modalidades de assistência de enfermagem predominantes no período de 1945 a 1980. Ribeirão Preto, 1984 (mimeo).

12. NOGUEIRA, M. G. IR. A formação do auxiliar de enfermagem na realidade brasileira. Rev. Bras. Enfermagem, v. 18, n. 4, p. 371-387, out. 1965.

13. OLIVEIRA, M. I. de. Fases de crescimento e desenvolvimento profissional. Rev. Bras. Enfermagem, v. 16, n. 6 p. 453-460, dez. 1963.

14. PEPLAU, H. E. Interpessonal relations in nursing. New York: G. P. Putnam's, 1952.

15. SILVA, AL. C.; BARROS, S. M. P. F. de; VIEIRA, T. T. Marco conceitual e estrutural dos currículos de cursos de graduação em enfermagem. CONGRESSO BRASILEIRO DE ENFERMAGEM, 31, 1979, Fortaleza. Anais. Fortaleza: ABEn, 1979.

16. SILVA, A. X. de. Enfermeiro-profissional autônomo ou subsidiário, CONGRESSO BRASILEIRO DE ENFERMAGEM, 1979, Fortaleza: ABEn, 1979. p. 76.

17. SIMSONS, O. M. V. (org). Experimentos com história de vida (Itália-Brasil). São Paulo: Vértice, Inbunas, 1988. p. 195.

18. TURKIEWICZ, O. Primado do espírito na profissão. Rev. Bras. Enfermagem, v. 18, n. 4 p. 306, out. 1965.

19. ViettA, E. P.; Bueno, L. V.; MAgAlhães, M. F.; HeCK, A. R. Técnica do depoimento pessoal: resgate da evolução da assistência de Enfermagem no hospital-escola (déc. 50) In: PROGRAMA RESUMO ENCONTRO INTERNACIONAL "Pesquisa em Enfermagem: uma questão de Saúde", São Paulo, 1992. Programa e resumos. São Paulo: Escola de Enfermagem USP, 1992. p. 121. 